\title{
Adiciones bibliográficas al corpus de poesía judeoespañola admonitiva
}

\author{
Carmen VALENTíN* \\ Grinnell College
}

En 1977, Elena Romero y Leonor Carracedo publican el artículo «Poesía judeoespañola admonitiva» ${ }^{1}$, donde definen esta poesía como «aquella cuyo propósito es el de apartar al hombre del mal camino, criticando sus malas costumbres, para llevarle a la práctica de las virtudes» ${ }^{2}$. El artículo se convirtió en la primera aparición del corpus poético que constituía este subgénero, dando noticia de las doce coplas de las que se sabía por entonces. El presente artículo viene a completar esta primera aportación al presentar las versiones aljamiadas impresas de los nuevos poemas descubiertos desde entonces ${ }^{3}$.

Como ya señalaron Romero y Carracedo ${ }^{4}$, en la historia de la poesía admonitiva sefardí, se pueden distinguir tres etapas, que se corresponden con sus tres siglos de vida textual documentada, cuyos límites no siempre quedan bien perfilados.

*valentin@grinnell.edu

${ }^{1}$ En Sef 37 (1977), págs. 429-451.

2 Romero y CARracedo, «Poesía», pág. 429.

${ }^{3}$ En estos años, Elena Romero ha dedicado parte de su trayectoria profesional a la publicación de artículos dedicados a la producción poética de Hayim Yom-Tob Magula, destacado creador de coplas moralizantes, en los que ha dado cuenta de los seis poemas escritos por él. Toda esta labor investigadora ha quedado recogida en su libro: Seis coplas sefardies de «castiguerio» de Hayim Yom-Tob Magula, con la colaboración de Carmen VALEnTín (Madrid 2003). Además de los textos de Magula, hemos tenido noticia de otras coplas de castiguerio a través de artículos, revistas, cancioneros o recopilaciones. En «Poesía judeoespañola admonitiva: notas para su caracterización», Sef 66 (2006), págs. 443-470, yo misma intento aportar más datos a la caracterización del subgénero en conjunto tras editar y estudiar las coplas del corpus escritas con el esquema estrófico del zéjel.

${ }^{4}$ Ver también Elena Romero, «Las coplas sefardíes: Categoría y estado de la cuestión», en Actas de las Jornadas de Estudios Sefardies (Cáceres 1980), págs. 69-98. 
El siglo XVIII nos ofrece las llamadas «Coplas de Tojáḥat megulá»: Las malas costumbres (1739)5, Los extremos de la vida (1739), Visiones divinas (1739), El mundo al revés (1787), Un mundo nuevo (1787), Las edades del hombre (1787).

Estos poemas, compuestos por Hayim Yom-Tob Magula, aparecen como corpus editorial entre los años 1739 y 1858 -aunque la edición de Salónica de 1787 es la única que recoge los seis textos juntos-.

Las malas costumbres critica la falta de cumplimiento de los principios y prácticas del judaísmo. Los extremos de la vida recoge la idea de la fugacidad de la existencia humana y el escaso valor de lo mundano, pues todo se pierde con la muerte. El sufrimiento del hombre pecador se recuerda desde dos diferentes perspectivas en Visiones divinas y Las edades del hombre, ejemplificadas en ésta todas las etapas del devenir humano. En El mundo al revés y Un mundo nuevo, el autor se sirve de sus propias experiencias personales para plasmar la admonición al criticar, en la primera, la incomprensión de la gente ante su oficio de corrector de costumbres y alegrarse, en la segunda, por que el pueblo judío ya pueda vivir en paz.

Las tres coplas más modernas de este corpus no figuran en el artículo de Romero y Carracedo; si bien, se da debida cuenta de ellas en el libro de Romero Seis coplas sefardíes de «castiguerio» de Hayim Yom-Tob Magula.

Durante el siglo XIX, la poesía admonitiva continúa con los mismos temas e igual sentimiento religioso que caracterizaba la anterior. Los poemas de este momento son conocidos de modo general como Coplas de musar ["moral"] -algunos de ellos muestran este epígrafe; así, «Cantiga de musar» se lee en folio de una de las versiones aljamiadas de Diálogo entre Dios y la nación-. Normalmente, las coplas aparecen incluidas en libros de literatura moralizante o en colectáneas de poesía. Los textos datados en este siglo son: Los pecados del hombre (1830), Contra los soberbios (1839), El buen obrar (1853), Azote de impíos (1858), La última jornada (1858), Diálogo entre la Ley y el hombre (1858), Los pesares del alma (1861), Diálogo entre Dios y la nación (1869), Vanidad de las riquezas (1876), Tras el fuego de 1890 (1891), Por la senda del Criador (1896), Tras el pedrisco de 1899 (1899).

Diferentes copleros firman estas coplas, aunque algunas nos han llegado anónimas. En ellas se da la crítica de los vicios mundanos, se recuerda el sufrimiento del hombre pecador, se reafirma el deseo de seguir el camino de Dios y se muestran las esperanzas de recompensa por hacerlo. Además no olvidan la

\footnotetext{
${ }^{5}$ Doy los títulos que aparecen en Elena RoMEro, Bibliografia analítica de ediciones de coplas sefardies (Madrid 1992). Indico la fecha de la versión aljamiada más antigua de la que tenemos noticia. 
fugacidad de la vida y la crueldad de la muerte. Las dos únicas coplas admonitivas de estructura dialogada se escribieron en este periodo.

El siglo xx se caracteriza por dar a conocer coplas con temas cotidianos o hechos contemporáneos -tendencia que ya se inició a finales del XIX-, lo cual queda reflejado en el epígrafe Coplas del felek ["mundo, actualidad"], que encabeza algunas de ellas como, por ejemplo, El buen obrar. Ese hecho hace difícil establecer el límite entre las coplas admonitivas y las noticieras o descriptivas de nuevas costumbres. Debido a ello, he decidido limitarme en este artículo a esas coplas hechas al estilo de las antiguas; es decir, esas cuyo contenido se centra en la llamada de atención del coplero para que el pueblo judío corrija costumbres y evite la destrucción que su comportamiento pecaminoso causa sin servirse de una descripción más o menos detallada de determinadas nuevas costumbres o personas y hechos contemporáneos concretos, aunque en algunos de estos poemas también se pueda percibir un tono doctrinador. Por lo tanto, de momento y a la espera de un estudio más detallado de estos subgéneros, considero éstas como pertenecientes a los otros dos grupos temáticos mencionados arriba ${ }^{6}$. Tras seguir este criterio de selección, aplicado del mismo modo a las coplas escritas en los últimos años del siglo XIX, se encuentra una única copla de admonición para el siglo xx: Tras las desgracias de 1913 (1913).

A continuación, presento las adiciones al corpus de poesía judeoespañola admonitiva.

\section{EL BUEN OBRAR}

La versión más antigua de esta copla no se recoge en el artículo de Romero y Carracedo, donde sí se da cuenta de sus otras dos versiones aljamiadas:

1. La publicada en Conplas de el felek de Šabetay Alaluf; Salónica, ca. 1853 (BAECS 76) ${ }^{7}$; en hs. 1b-4b.

El libro es la edición de esta copla. Hemos consultado fotocopia del ejemplar de la Jewish National University and Library con signatura R87A526

En portada del libro se destaca su contenido admonitivo:

\footnotetext{
${ }^{6}$ Igualmente he dejado aparte esas coplas «editoriales» que aparecen en libros de moral destacando los provechos de su lectura. Me refiero a Los provechos de meldar (1742), Los provechos del «Cab hayasar» (1823), Los provechos del «Séfer hayasar» (1823) y Los provechos del «Perí es hadar» (1824).

${ }^{7}$ Número con el que aparece en Romero, Bibliografia.
} 
Sabréš hermanos que ditas conplas las vide que son palabras justas y cośa tocante para el felek de agora y todo es musar y demandas buenas de el Dio $[\ldots]$

\section{LOS PESARES DEL ALMA}

La copla se nos ha dado a conocer por una única versión:

1. La publicada en Séfer Širá ḥadašá de Ḥiźquiyá Šemuel Tarica; Esmirna, 1861 (BAECS 98); en hs. 16a-18b.

Se trata de un libro compilación donde, junto a varios piyutim, aparecen doce coplas de temas diversos, entre las cuales descubrimos ésta de castiguerio. Hemos consultado fotocopia del ejemplar de The Library of Congress (Washington) con signatura 136.

En portada del libro se lee:

$$
\text { [...] cantos y alabanzas en honor de } \operatorname{los}_{\text {justos }}{ }^{8}[\ldots]
$$

Precede al poema la indicación del laḥan con el que debe ser entonado: «Šir lahan ["poema al son"] Hija mía, mi querida»; y, a continuación, se apunta el acróstico, el cual incluye el nombre del autor: «[...] "al séder alef bet aní Šemuel Tarica vejú" [vejuleh, "etcétera", lit. "todo ello"] ḥaźac».

El texto poético marca el contraste entre el estado de gracia que tiene el alma antes de nacer y su vagar como aliada del mal cuando está en la tierra. El coplero insiste en la tenacidad del hombre por llevar una vida apartada de los designios de Dios, le advierte sobre el escaso valor de los lujos que persigue porque todo, al igual que él, nace de la tierra y en ella se desvanece con la muerte y, por último, le recuerda cuál será su castigo en la otra vida por aliarse con el mal.

El contenido de la copla se desarrolla en 51 estrofas, a las cuales precede una introductoria:

$$
\begin{aligned}
& \text { De verme con muncha fatiga } \\
& \text { ordení esta cantiga, } \\
& \text { con ella se castiga } \\
& \text { el hombre criado de la tiera. }
\end{aligned}
$$

Las estrofas presentan rima zejelesca $a a a b$ con cuatro versos de tendencia octosilábica y vuelta en tiera.

\footnotetext{
${ }^{8}$ Copio la traducción que del texto hebreo hace Romero, Bibliografía, pág. 61.
} 
El acróstico comienza en la estrofa 1 y sigue hasta la 36: alefato completo en orden directo + «aní Šemuel Tarica». Después se interrumpe hasta la antepenúltima estrofa, donde de nuevo se inicia para leer «haźac». El «Ah» que inicia la estrofa 5 se escribe con he para no alterar el acróstico.

\section{POR LA SENDA DEL CRIADOR}

La copla nos ha llegado a través de una sola versión aljamiada impresa:

1. La publicada en Historia temerośa de un hijo muy preciośo; Jerusalén, 1896 (BAECS 168); en págs. 53-56.

El libro contiene como colofón esta copla de castiguerio. Hemos utilizado fotocopia del ejemplar de la Jewish National University and Library con signatura $31 \mathrm{~V} 4315$.

En la portada del libro leemos la intención moralizante con la que fue escrito:

Honrados señores, seguro que en meldando dita historia prendenrán temores y sabores ["gustos"] y de sus bocas no mancarán ["faltarán"] loores al patrón de el mundo de los altares, el que mos aúne muestros corazones, źejut ["mérito"] de muestros antigos padres, mos arecógga a muestros lugares [...]

que está en estrecha relación con el contenido de la copla.

Precede al texto poético la indicación del acróstico: «Dita compla es "al séder alef bet», y de su melodía: «lahan Biteta iyuní ["Has expresado mi meditación"]». Al final del poema leemos, a modo de colofón, la declaración de autoría donde se dice que Ya'acob Hay (Franco) es el autor de la copla:

«B “ḥ"t [Be'érrat hael (o hašem) yitbaraj, "Con la ayuda de Dios”] dita compla la arecentí ["compuse"] yo al gusto de todos los queridos

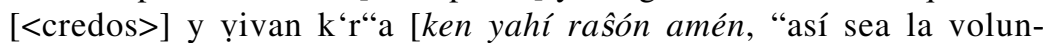
tad (de Dios), amén"]. Haŝeb"í [haŝa'ir, "el joven"] Ya“acob Ḥay ["Vivo"] s"t [sofé tav, lit. "su fin debe ser bueno"] (hamejuné [lit. "el llamado", "el apodado"] Franco) n' [ben 'hijo de'] abá morí ['mi padre y maestro'] Mošé Ya 'acob Miźrahí ["Oriental”] źlh"h [zijronó (o zijró) leḥaé ha 'olam haḅá, "que su memoria tenga vida en el mundo venidero"].

La copla señala los preceptos y obligaciones que todo buen judío ha de tener siempre presentes y, por supuesto, cumplir, al tiempo que enumera los beneficios y la recompensa que Dios otorgará al seguir su camino. 
La admonición llega en 22 estrofas de rima zejelesca $a a a b$ con cuatro versos anisosilábicos con vuelta en la palabra criador (las dos primeras estrofas son de cinco versos).

El acróstico presenta el alfabeto completo en orden directo.

\section{TRAS EL PEDRISCO DE 1899}

La copla nos ha llegado a través de una única versión aljamiada impresa:

1. La publicada en Complas nuevas por el pedrisco de Salonic de Ya'acob Yoná; Salónica, ca. 1899 (BAECS 173); págs. 5-8.

Es un libro donde se editan cuatro coplas y unos proverbios morales. Hemos manejado fotocopia del ejemplar de la Yeshiva University Library (Nueva York).

En portada del libro se lee:

En esta guemará ["librito"] contiene lo sigüente ... un cante moderno [Tras el pedrisco de 1899] [...]

Esta copla tiene un contenido muy similar a El buen obrar, con la que guarda numerosas semejanzas de formulación. El coplero, Ya'acob Abraham Yoná ${ }^{9}$, suplica a sus hermanos que dejen de hacer el mal y regresen al camino de Dios, pues en su mal comportamiento está el origen de las desgracias que están cayendo sobre su pueblo, como ésta del pedrisco. Asimismo, pide clemencia a Dios para que les otorgue el perdón y le ruega que no mande más calamidades.

El texto poético cuenta con 22 estrofas de cuatro versos de tendencia dodecasilábica, formados, en general, por dos hemistiquios de seis sílabas (pero también de cinco, siete y ocho), con rima monorrima $A A A A$.

El poema presenta acróstico alfabético completo en orden directo. Se nota la sustitución de he por alef al escribir la palabra inicial «El» en estrofa 5.

\section{TRAS LAS DESGRACIAS DE 1913}

Conocemos la copla por una sola versión aljamiada impresa:

\footnotetext{
${ }^{9}$ Moshe Atrias, «Jacob Jona - Wandering Minstrel of Salonica» [en hebreo], Sefunot 15 (1971-1981), págs. 153-202. 
1. La publicada en Complas muevas del felek preśente; Salónica, 1913 (BAECS 216); en columnas a-b.

Este folleto es la edición de dos coplas dedicadas a las desgracias de 1913. Hemos consultado fotocopia del ejemplar del Ben Zvi Institute con signatura S-70.

En cabecera de la hoja leemos:

Complas muevas del felek preśente por el año de šečentos y setenta y tres: la guera, la hambrera y la escapadura de la holera ['cólera'] [...]

Precede al cuerpo de la copla:

Y este cante es tocante al felek de agora.

Este poema tiene un contenido muy similar a El buen obrar y Tras el pedrisco de 1899, con las que guarda abundantes semejanzas de formulación. De nuevo, Ya acob Abraham Yoná ${ }^{10}$ pide a sus hermanos que abandonen el pecado y sigan la estela de Dios, pues su mal comportamiento es la causa de las desgracias que están ahogando a su pueblo. Además, exhorta a Dios para que les perdone.

El texto poético cuenta con 22 estrofas de cuatro versos de tendencia dodecasilábica, formados, en general, por dos hemistiquios de seis sílabas (pero también de cinco y siete), con rima monorrima $A A A A$.

La copla presenta acróstico alfabético completo en orden directo, donde el coplero no altera el acróstico al escribir la palabra inicial «El» de la estrofa 5 con he.

${ }^{10}$ AtTiAs, «Jacob». 


\section{RESUMEN}

En este artículo se presentan las versiones aljamiadas impresas de las coplas admonitivas descubiertas desde el año 1977, cuando Romero y Carracedo hicieron la primera presentación de conjunto de este corpus en su artículo «Poesía judeoespañola admonitiva».

Palabras Clave: Coplas, poesía, admonición, aljamía.

\section{SUMMARY}

In this article, I present the "Aljamiado" printed versions of the "Coplas Admonitivas" discovered since 1977, the year when Romero and Carracedo published a first presentation of this corpus in their article "Poesía judeoespañola admonitiva."

Keywords: "Coplas,” Poetry, Admonition, “Aljamía.” 